\title{
The Study on Ecological Status of College Physical Education Pengxi Yan ${ }^{1, a}$ \\ ${ }^{1}$ Xi'an International University, Xi'an, Shaanxi, 710077 \\ a email
}

Keywords: University, Physical Education, University Ecology, Current Situation, Measures

\begin{abstract}
In recent years, China's comprehensive national strength is increasing and at the same time, government is increasing the focus on education, especially in previously marginalized Physical Education. Although the physical education curriculum from primary school to university has been set up, but because it is limited to the understanding of physical education in the limited time students, so the school will be more willing to focus mainly devoted to teaching, such a situation makes that there is a physical education some problems, effect of physical education is not very satisfactory. Although college sports is offered more the attention than the primary, middle and high school physical education curriculum, but compared to other major professional, there is still a gap, this reality has led the University of Physical Education is not very ideal, in which the lack of ecological education a very serious problem. Therefore, this status quo Ecology University of Physical Education in-depth thinking, and presented their views, hoping to better carry out the teaching of university sports, to promote the further development of ecological education.
\end{abstract}

\section{Introduction}

In people's living standards continue to improve, based on the growing pursuit of their own health, and in order to ensure their own health, for sports emphasis gradually increased, so that the environment in the background, there is growing emphasis on physical education teaching. In the past, physical education, teachers will be placed on its own dominant position, ignoring the student body, while also not reasonable to conduct teaching according to the teaching environment, so that makes college sports teaching ecology missing, teaching imbalance phenomenon is more prominent, so that makes the teaching status quo of physical education in efficiency is not high, and the teaching effect is not very satisfactory. Students as the desired country, if not strong physique, then later work will inevitably be limited by physical factors, and thus can not give full play to their ability, in view of such circumstances, the University of Physical Education in the Present Teaching Ecological Problems for detailed and find the right solutions, in order to promote sports education is scientific and rational is very necessary, but imperative.

\section{The Concept of Ecological Sports Teaching}

In many professional education, which sport as a discipline is not highly regarded, they obtain teaching resources, support is limited, but also has a certain influence on the teachers' attitude such a case, we do not pay attention when some PE teachers gave rise to self-denial, that their teaching is not very important, essential, and produce the slack mood, seriously affected the Sports Teaching. Related scholars recognize the problem, so the physical education teaching conducted in-depth studies and research in the proposed PE teaching ecology. The so-called sports teaching ecology, refers to the ecology theory as a basis for research on teaching, combined with the overall concept and the overall concept to promote physical education teaching theories can be further developed [1]. This idea is in the 1980s, when they were raised after the presentation, this concept has been most people agree, but in the actual implementation process, since the scope of Physical Education involved more widely, its ecosystem is more complex so there have been ecological sports teaching Lack in carrying out the process. Sports ecosystem contains more, many aspects was, teaching space, facilities and teaching concepts, etc., in many respects, the human is the most important part of a person referred to here mainly refers to the teachers and students, and students, as well as 
teachers and teacher, who has this factor in physical education ecological effects can not be ignored, only to realize the coordinated development of man and the teaching environment and other factors, physical education ecology Absence can be solved.

\section{College Sports Teaching in Ecology Absence}

Students in elementary and junior high school have access to the sports learning, but in the actual teaching, because schools do not attach importance to teaching, but students do not want to waste more time in physical education learning, many students think of the physical education curriculum conduct is not necessary, but under the influence of such thinking, for students interested in learning the sport is not high, not teaching students to treat sports optimism allows students at the university level is still not too keen on sports study. Such a situation occur fully explain the students sports consciousness imbalance in ecology theory as the basis for the analysis can see that the elements involved in university physical education to be more, but these elements do not appear to any one of the elements balance, will have on the overall ecosystem impacts, so that students as a sports education ecosystem important aspect of students' interest in physical education teaching is not high on the system, the overall balance of the ecology had an impact, especially for teachers influence, teachers and students who are the elements of this component, when students are not interested in learning the sport, its negative attitude will affect teachers' attitude, so teachers in teaching on the perfunctory, leading students more do not like physical education, ultimately creating a vicious cycle, a serious impediment to the further development of Physical Education.

College Physical Education and teaching subjects presented ecological and social these two factors have a direct link, the teacher is the main university sports teaching, teachers teaching ideas and methods of peer teaching effect on fertility has a critical influence, and universities rich cultural atmosphere, the legacy of historical and cultural factors will have a major impact on the subject of teaching is teachers teaching ideas, etc., so that, at the University of Physical Education, leading teaching ecology is that the main reason for lack of teachers teaching more traditional behind. Because of exam-oriented education system, many schools, teachers and even parents to allow children to be admitted to an ideal university, later to have a good diploma, attaches great importance to students' knowledge of the main subjects of study, and some have not been included in the examination subject is very neglected, so the idea makes the marginalization of Physical Education in Education and Teaching, compare its underground status, and in order to get the main teachers are better able to carry out teaching, master teachers and sports teachers salary, also there is a gap, so the reality blow to the enthusiasm of PE teachers work. Such situation makes the sports ecosystem, nature and social factors appear anti-ecological phenomena, to carry out physical education teaching to enhance students' physical fitness and not a larger role.

In physical education, we want to make their teaching to achieve the desired effect, it is necessary to clear teaching goals and objectives as the center to develop targeted teaching programs, but during the actual conduct of teachers in physical education teaching in, but and there is no clear teaching objectives, teaching method used is relatively backward, so the situation is such that it makes physical education teaching can not arouse students' interest in learning, while students in the learning process can not obtain the corresponding gain [2]. Physical education goals are not clear for the issue, and the persons in-depth analysis found that the relationship between this issue and between teachers and students is not very close closely linked, teachers and students disharmony, then they can not teachers identifying the needs of students, teachers and students can not understand the good intentions, the PE teaching result is not satisfactory, the problem is more serious ecological missing.

\section{The University of Physical Education Ecological Development Measures}

Sport at the University of ecological systems, social factors is one very important part, we want to promote the development of university sports ecological, social factors from the start, improve the university leaders and teachers of physical education in the degree of attention, invest more the 
effort to carry out this teaching, in order to promote physical education teaching can achieve better results. Therefore, in the course of conducting the University of Physical Education, the importance of physical education should be on the publicity so that more people recognize the importance of physical education, through feedback to encourage social forces to further strengthen the School of Physical Education. At the same time, it should be within the campus physical education advocacy, to enable students to understand the positive role of sports knowledge to learn, in order to help teachers to better play the role of teaching. In addition, during the process of teaching the teachers, we should take effective measures to mobilize the initiative of students, so that students can actively participate in the study, so that students can learn the knowledge of the process Physical exercise their bodies, improve their physical fitness He has a good health, study and work in the future in order to fully achieve self-worth, as a modest contribution to the development of national power.

For the limited importance of physical education teaching time, thus making the PE teaching still remained a lot of stale content, thus affecting the development of ecological sports teaching, sports education and hinder progress. For this situation, the university should take effective measures to promote the teaching change the concept of PE teachers, you know, physical education teacher is the subject of the implementation of sports teaching, and its ideas directly affect the effect of physical education, the teacher's role is can not be ignored in this case, PE teachers should redefine its role, with full respect for the dominant position of students in teaching students to respect, to conduct a student-centered teaching PE [3]. Teachers respect for students is the main content of their ideological transformation, when the teachers to respect for life, and in order to improve students' physical fitness and work time, the value of teachers to be reflected. Therefore, the teacher during the teaching process should be based on the concept of ecology as a basis for teaching, thus contributing to the sustainable development of students.

Teachers and students are the main parts of PE teaching, whether it is missing two portions which part of the Sports Teaching will not achieve good results, but if the relationship between teachers and students is relatively stiff, it will also affect teaching effect for such a situation, in promoting sports teaching ecological development, it is necessary to build a good teacher-student relationship. Teachers should be equality perspective and student exchanges, rather than a superior angle top view of students, and students should not be treated in a hostile attitude to teachers, but teachers should be as their friend, teacher and students open our hearts to each other when the teachers on the knowledge to the students' needs, students willing to accept in order to knowledge, and appreciate the teachers are doing. Therefore, the promotion of teachers and students to communicate, so that they can establish a harmonious relationship is one of the major measures to achieve ecological development of the sports university.

\section{Conclusion:}

In summary, in university teaching, the status of physical education teaching is gradually rising, the college physical education gives more ecological importance, so the lack of physical education in the presence attracted attention, and in order to solve this problem, take colleges effective measures to further strengthen the importance of physical education teaching force and promote the transformation of the concept of teaching so that the students can actively participate in physical education, and cherish a grateful heart to accept the teacher to explain the contents, to improve their physical fitness at the same time and improve their own personality training, for college students and lay a good foundation for the physical education development.

\section{References}

[1] Jiang Xiuying, Wang Zhimin. Deficiency and Reconstruction of the University Physical Education in the New Ecology [J]. Lanzhou University (Natural Science), 2015, 29 (1): 66-68.

[2] Lan Ruigao, Wang Biao. Universities' Physical Education Ecology Reconstruction - Based on the ecology [J]. Technology Monthly, 2012, (11): 131-132. 
[3] Yuan Weiyu, Yang Guang, Liu Yu. Study on Physical Education Teaching Mode under the Perspective of Ecology to develop new ideas [J]. Research and education programs (new teaching), 2016, (11): 19. 